\title{
STRUCTURAL (SUPER)PLASTICITY OF MAGNESIUM MATERIALS
}

Superplastic behaviour of two magnesium alloys QE22 and EZ33 having a grain size of $\sim 1 \mu \mathrm{m}$ was studied at a temperature of $420{ }^{\circ} \mathrm{C}$ and in the strain rate interval from $1 \times 10^{-4}$ to $1 \times 10^{-3} s^{-1}$. The substructure of samples was analysed by the transmission electron microscope before and after deformation. The substructure of samples exhibits an existence of particles in the grain boundaries. These precipitates are very stable even at high deformation temperature and they are reason for the relatively high ductility of alloys. Observed ductility of the WE54/SiCp composite is much lower due to the existence of ceramic particles in the grain boundaries. They inhibit the grain boundary sliding and are the reason for the cavitations and early fracture of the composite.

Keywords: Magnesium alloys, Magnesium alloy based composite, Strain rate sensitivity, Electron microscopy, Superplasticity, Threshold stress

\section{Introduction}

Low density of magnesium alloys and relatively high specific strength are the main advantages of these materials. Magnesium alloys and composites are used in different industrial applications. As magnesium is recyclable, its extensive usage can minimize the negative impact on the environment due to non-degradable plastic wastes. Magnesium materials have low ductility at ambient temperature. This is a consequence of the hexagonal close-packed (hcp) crystal structure with a limited number of operative slip systems. The plasticity of magnesium alloys and composites increases at elevated temperatures where additional slip systems become active. However, low ductility of magnesium alloys prevents their application hence; the enhanced ductility of magnesium materials is of a special interest [1-4]. It is known that the fine grain size $(d \leq 10 \mu \mathrm{m})$ stable at higher temperatures is a main structural requirement for the occurrence of superplasticity. All characteristics of superplasticity (relative elongation to failure $\varepsilon_{f}$, flow stress $\sigma$, strain rate sensitivity of flow stress $m$, optimum strain rate for superplasticity and optimum deformation temperature for superplasticity) depend on the grain size. Fine grain structure with the grain size less than $10 \mu \mathrm{m}$ may be obtained by various methods such as phase transformation, recrystallisation, forming of the microduplex structure or severe plastic deformation (equal channel angular pressing, reciprocating extrusion) [5-10]. Structural superplasticity was estimated in several magnesium alloys especially in alloys of the AZ series [11-13] or Mg-Li alloys [14-15]. The superplasticity phenomenon was also observed in ZK60 alloy [16], WE54 alloy [17] and QE22 alloy [18].
In papers $[18,19]$ the influence of preliminary thermomechanical treatment (hardening, overageing and hot extrusion) on the grain size was investigated. This prior thermomechanical treatment influences the number of recrystallisation nuclei and so the resulting grain size.

The aim of this work is to study the microstructure and substructure of two magnesium alloys containing rare earth elements (RE) and $\mathrm{Zr}$, which exhibited better superplastic properties in comparison with alloys containing $\mathrm{Al}$. The aim is also to find the main features influencing the superplastic behaviour and limiting factors for lower plasticity of particles reinforced composite with the Mg alloy matrix.

\section{Materials and experimental methods}

QE22 (Mg-2Ag-2RE-Zr), EZ33 (Mg-2.5Zn-3RE-Zr) magnesium alloys and WE54 (Mg-4Y-4RE) reinforced with $\mathrm{SiC}$ particles were used in this study. Cylindrical QE22 and EZ33 specimens with a diameter of $72 \mathrm{~mm}$ and a length of $80 \mathrm{~mm}$ were cut from ingots and exposed to homogenisation treatment at $470{ }^{\circ} \mathrm{C}$ for 10 $\mathrm{h}$ with the subsequent cooling on the air. Due to low diffusion rates of solute atoms in the magnesium matrix the alloys were simultaneously quenched. Precipitation ageing was conducted in the temperature range from 200 to $380{ }^{\circ} \mathrm{C}$ for 10 hours. After that, the aged specimens were preheated at $350{ }^{\circ} \mathrm{C}$ and then hot extruded. This device consists of the press with the rated strain of $4000 \mathrm{kN}$ and the tube furnace which heats instrumental rigging

\footnotetext{
* Zuzanka Trojanova ${ }^{1}$, Zoltan Szaraz ${ }^{1}$, Oksana Padalka ${ }^{1}$, Talant Ryspaev ${ }^{2,3}$ and Pavel Lukac ${ }^{1}$

${ }^{1}$ Department of Physics of Materials, Faculty of Mathematics and Physics, Charles University in Prague, Czech Republic,

E-mail: ztrojan@met.mff.cuni.cz

${ }^{2}$ Institute of Welding Engineering and Cutting Manufacturing Processes (ISAF) Clausthal University of Technology, Clausthal-Zellerfeld, Germany

${ }^{3}$ Kyrgyz State Technical University, Kyrgyz-German Technical Institute, Bishkek, Kyrgyzstan
} 
(container with a diameter of $75 \mathrm{~mm}$, matrix and punch). Hot extrusion was performed in two steps with the extrusion ratio of 20 and 26. Samples for deformation experiments were machined from the extruded bars.

Composite WE54/SiC containing 13 vol. \% SiC particles was processed by a powder metallurgy method (PM). Extrusion billets were prepared by mixing of the matrix powder with $\mathrm{SiC}$ particles in an asymmetrically moved mixer with subsequent milling in a ball mill. The powder was encapsulated in $\mathrm{Mg}$ containers and extruded to rods at $400{ }^{\circ} \mathrm{C}$. The composite samples were not thermally treated. Tensile specimens with a gauge length of $10 \mathrm{~mm}$ and a gauge diameter of $6 \mathrm{~mm}$ were machined with the tensile axis parallel to the extrusion direction.

The strain rate sensitivity parameter $m=\left(\frac{d \ln \sigma}{d \ln \dot{\varepsilon}}\right)_{T}$ was estimated by the abrupt strain rate changes (SRC) method [20]. SRC tests and tensile tests with a constant strain rate $(\dot{\varepsilon})$ were performed at temperatures from 300 to $500{ }^{\circ} \mathrm{C}$ and strain rates from $10^{-4}$ to $10^{-2} \mathrm{~s}^{-1}$. Experiments with the constant strain rate, where the cross-head speed continuously increases, significantly reduces the test time at low strain rates. The best conditions for superplasticity of the alloys were found at a temperature of $420{ }^{\circ} \mathrm{C}$.

Foils for Transmission electron microscopy (TEM) from QE22 and EZ33 alloys were thinned by the electro-polishing method using the TENUPOL 3 . The specimens were etched in the solution of $15.9 \mathrm{~g}$ of $\mathrm{LiCl}, 335 \mathrm{~g}$ of $\mathrm{Mg}$ perchlorate, $1500 \mathrm{ml}$ of methanol, and $300 \mathrm{ml}$ of butoxy-ethanol in the temperature range -55 to $-40{ }^{\circ} \mathrm{C}$. After electro-polishing, the foils were washed in methanol. To prevent the formation of an oxide surface layer, TEM foils of all experimental materials had to be stored in vacuum. Investigations of substructure of the materials were carried out with JEOL 2000FX. The transmission electron microscope operating at $200 \mathrm{kV}$ was equipped with an energy dispersive X-ray analyzer (EDAX), which provides the analysis of individual phase composition. Microstructure of WE54/SiC composite was studied using a light microscope Olympus and scanning electron microscope JEOL.

\section{Results and discussion}

\subsection{Microstructure of materials}

The grain size of the QE22 and EZ33 alloys was measured in the both as-cast and after thermo-mechanical treatment states. The average grain sizes of the as-cast alloys are higher than $100 \mu \mathrm{m}$ while in the QE22 and EZ33 alloys after the thermo-mechanical treatment, the grain sizes were reduced to $0.7 \mu \mathrm{m}(\mathrm{QE} 22)$ and $1.2 \mu \mathrm{m}$ (EZ33), respectively.

The substructure of QE22 and EZ33 alloys was investigated in the as-cast and after thermo-mechanical treatment states. Microstructure of the as-cast QE22 alloy consists of $\alpha$-grains decorated in the grain boundaries by the second phase particles. TEM revealed chains of smaller particles; containing $\mathrm{Nd}$ and $\mathrm{Ag}$ located at grain

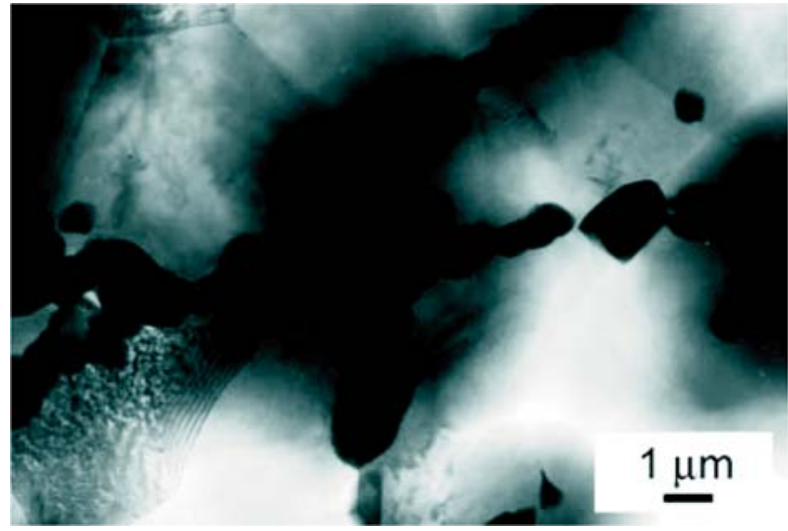

Fig. 1 TEM micrograph of the as-cast QE22 magnesium alloy showing particles of $\mathrm{Mg}_{3}(\mathrm{Ag}, \mathrm{Nd})$ phase situated in grain boundaries

boundaries (see Fig. 1). These particles were dissolved during homogenisation annealing. TEM showed only groups of smaller and bigger non-dissolved zirconium particles which are visible in Fig. 2a. These $\mathrm{Zr}$ particles are very stable and they were not influenced by the homogenisation treatment. Dislocations pinned at
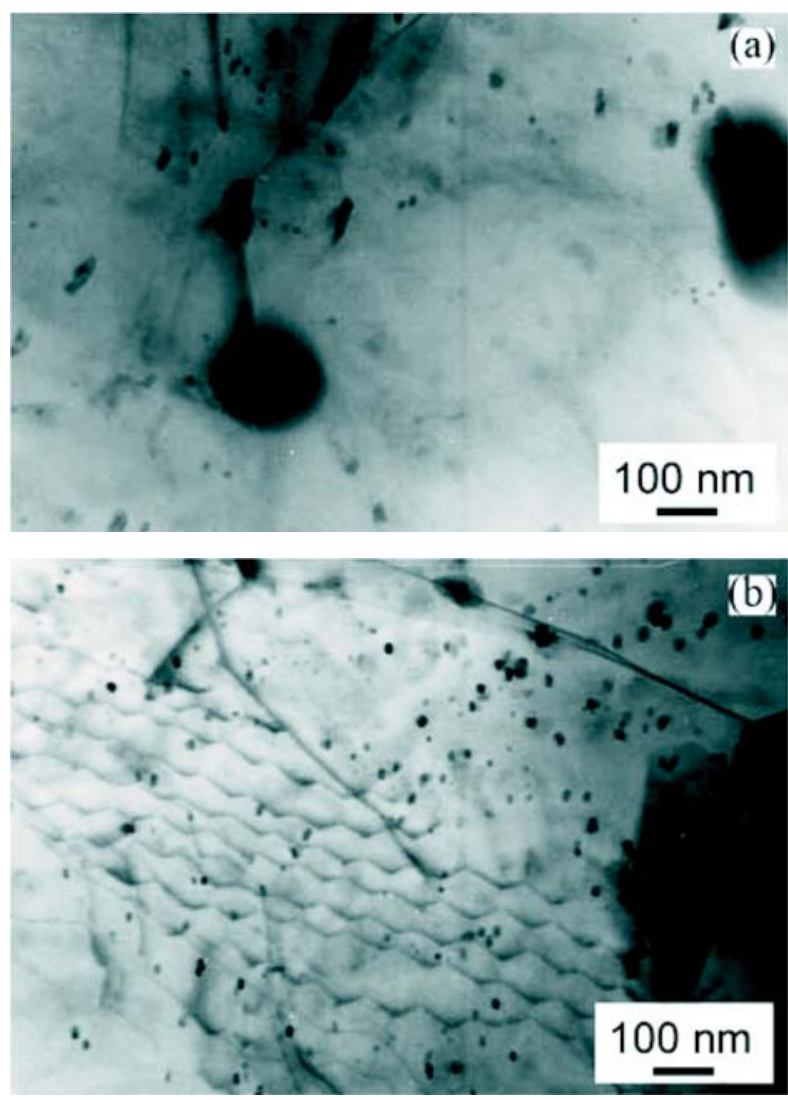

Fig. 2 TEM micrographs of the QE22 magnesium alloy after the homogenisation treatment: (a) fine $\mathrm{Zr}$ particles, (b) $\mathrm{Zr}$ particles in partially visible dislocation network 
$\mathrm{Zr}$ particles are also visible in Fig. 2b. After thermo-mechanical treatment (age annealing at $350^{\circ} \mathrm{C}$ for $10 \mathrm{~h}$ and hot extrusion) the particles at grain boundaries appeared again (see Fig. 3) and they were found again together with the smaller $\mathrm{Zr}$ particles also after deformation at $420{ }^{\circ} \mathrm{C}$.

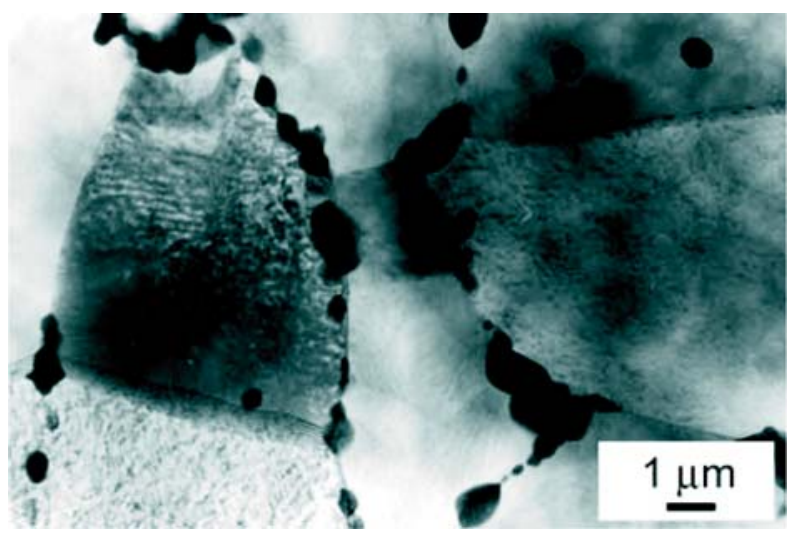

Fig. 3 TEM micrographs of the QE22 magnesium alloy after thermomechanical treatment showing chain of particles of $\mathrm{Mg}_{3}(\mathrm{Ag}, \mathrm{Nd})$ phase in grain boundaries

The interior of grains after deformation at $420{ }^{\circ} \mathrm{C}$ was clear without dislocations. Round particles appearing after the thermomechanical treatment were identified as $\mathrm{Mg}_{3}(\mathrm{Ag}, \mathrm{Nd})$ phase. There are two kinds of round particles of $\mathrm{Mg}_{3}(\mathrm{Ag}, \mathrm{Nd})$ phase: bigger particles with an average diameter of $0.2-0.5 \mu \mathrm{m}$ lying along the grain boundaries and in the triple points and the smaller particles with an average diameter of $50-100 \mathrm{~nm}$ situated in the grains interior. The obtained results of the $\mathrm{Mg}_{3}(\mathrm{Ag}, \mathrm{Nd})$ phase distribution agree with results in the paper [21] where similar two particle sizes were found in QE22 alloy after T6 temper (annealing for $5.5 \mathrm{~h}$. at $520^{\circ} \mathrm{C}$ and ageing $8 \mathrm{~h}$. at $205^{\circ} \mathrm{C}$ ). Particles placed at grain boundaries contribute to the microstructure stability hereby they hinder the grain growth during heating in the deformation machine and the self deformation. Precipitates in the grain boundaries were found also after the high temperature deformation practically unaffected.

The electron micrograph of the EZ33 alloy is shown in Figure 4 in the as-cast state. Fine $\mathrm{Zr}$ particles are visible. These particles remained unaffected by the thermo-mechanical treatment. The microstructure of EZ33 alloy after thermo-mechanical treatment exhibits small $\alpha$ grains containing fine $\mathrm{ZnNd}$ particles in the grain boundaries, very probably particles of $\mathrm{T}$ phase (Figure $4 \mathrm{a}$ ). Wei et al. studied the solidification path and phase constituents of alloys in the magnesium rich corner of the Mg-Zn-misch metal system [22]. They found that the T phase having a c-centred orthorhombic crystal structure exhibits a wide range composition of $\mathrm{Mg}, \mathrm{Zn}$ and $\mathrm{RE}$ depending on the alloy composition. The $\mathrm{Zr}$ particles (200-100 nm) were observed in the whole volume. In the sample of EZ33 after high temperature exposition during deformation the same particles were found, i.e. $T$ phase in the grain boundaries and small $\mathrm{Zr}$ particles in the grains interior (Fig. $4 \mathrm{~b}$ ). While dis-
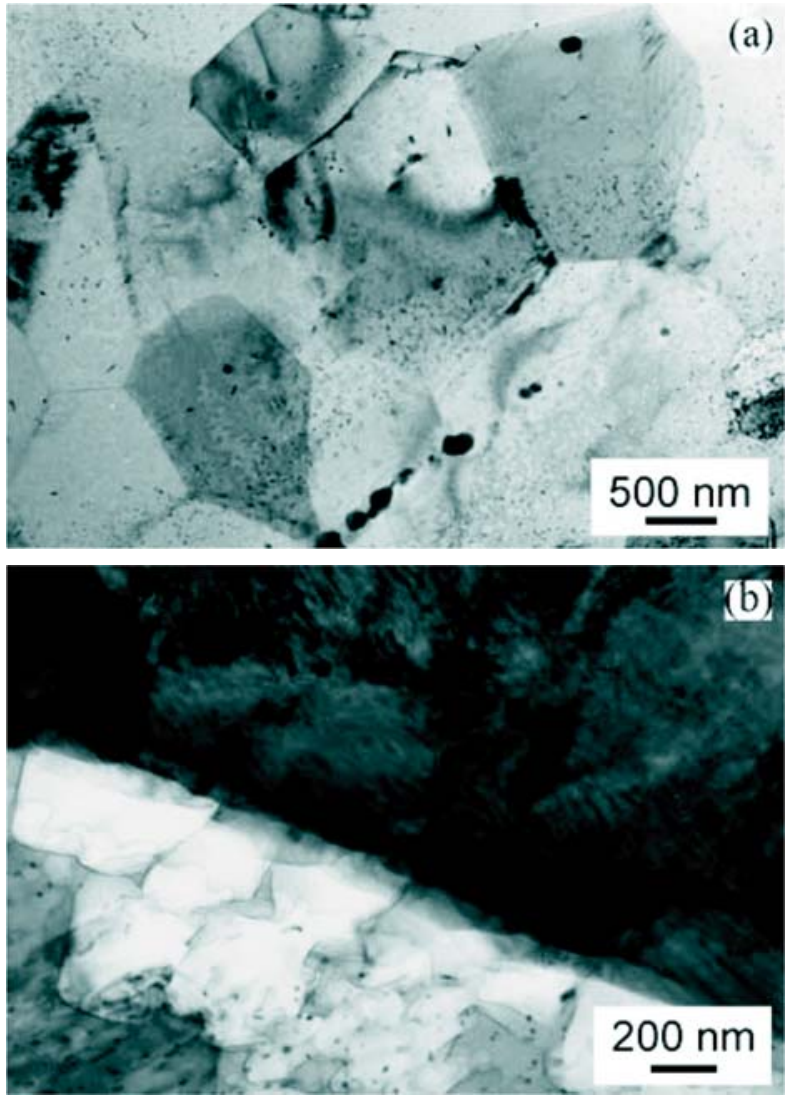

Fig. 4 TEM micrographs of the EZ33 magnesium alloy: after thermomechanical treatment (a) and after high temperature exposition during the deformation process (b)

locations in this material were present after the thermomechanical treatment (see Fig. 5), after the high temperature deformation no dislocations were detected. The average grain size of EZ33 alloy is relatively small $(1.2 \mu \mathrm{m})$, though it is even smaller $(0.7 \mu \mathrm{m})$

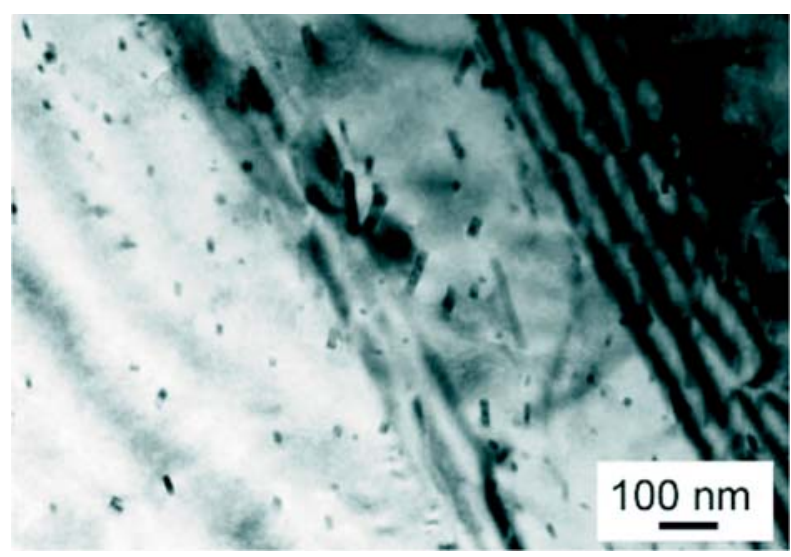

Fig. 5 TEM micrographs of the EZ33 magnesium alloy after thermo-mechanical treatment showing resistance to dislocation motion by the $\mathrm{Zr}$ particles 
in QE22 alloy. Such a difference between the grain sizes in the alloys can be caused by the presence of alloying element $\mathrm{Nd}$ besides Zr. QE22 alloy contains mainly Nd among rare earth elements. Furthermore, fine precipitates of $\mathrm{Mg}_{3}(\mathrm{Ag}, \mathrm{Nd})$ phase are uniformly located also inside of grains. As such $\mathrm{Zn}$ (and rare earth) containing alloys are the major $\mathrm{Mg}$ alloy group where $\mathrm{Zr}$ is used as the grain refiner [23]. Although $\mathrm{Zr}$ has long been used as a notable grain refiner for $\mathrm{Mg}$ alloys [24] the mechanism of grain refinement by $\mathrm{Zr}$ is not yet completely understood. In the alloys, which do not contain $\mathrm{Al}$, small $\mathrm{Zr}$ particles remain unsolved in the $\alpha$-matrix and influence the grain nucleation during solidification or recrystallisation.

Figure 6 shows the microstructure of the $\mathrm{WE} 54 / \mathrm{SiC}_{\mathrm{p}} \mathrm{com}-$ posite. The as-extruded bar appears mainly constituted of very small equiaxed grains. The corresponding average grain size was found to be about $\sim 3 \mu \mathrm{m}$. The $\mathrm{SiC}$ particles (mean particle size $\sim 9 \mu \mathrm{m}$ ) were not uniformly distributed in the matrix; in many cases they formed clusters.

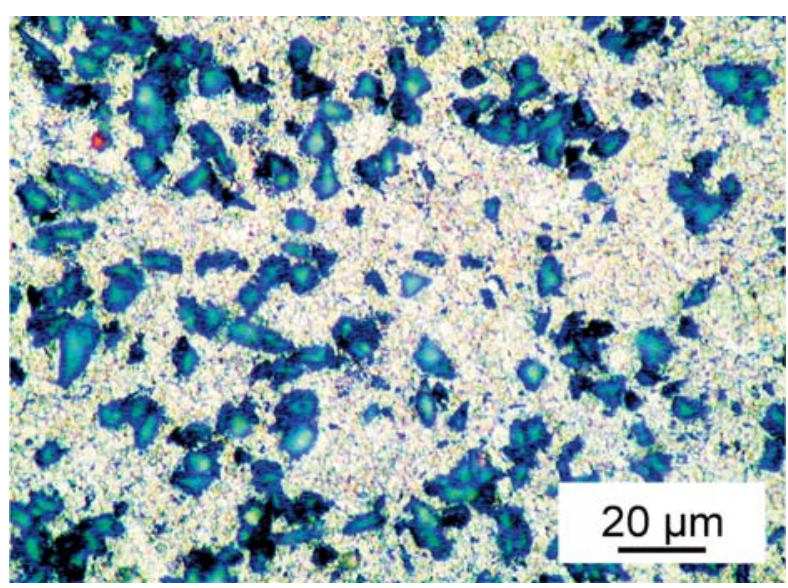

Fig. 6 Microstructure of WE54/SiCp composite

\subsection{Superplastic behaviour of alloys}

Values of the elongation to failure $\varepsilon_{f}$ introduced in Table 1 together with values of m-parameter were estimated at $420{ }^{\circ} \mathrm{C}$. The highest values of the elongation to fracture $\varepsilon_{f}=780 \%(\mathrm{QE} 22)$ and $710 \%$ (EZ33) were estimated at a strain rate of $\dot{\varepsilon}=3 \times 10^{-4} \mathrm{~s}^{-1}$. These values correspond to the highest values of the strain rate sensitivity $m=0.75$ (QE22) and 0.73 (ZE33) which were estimated at the same deformation conditions. As it follows from Table 1, the tensile elongations of all samples exceeded $200 \%$, which represents a substantial improvement over the poor room-temperature ductility, typical for magnesium alloys. The strain rate of materials deformed at high temperatures is done by a relationship of the following form:

$$
\dot{\varepsilon}=A \frac{G b}{k T}\left(\frac{b}{d}\right)^{p}\left(\frac{\sigma}{G}\right)^{n} D
$$

where $A$ is a dimensionless material constant, $G$ is the shear modulus, $b$ is the Burgers vector, $d$ the grain size, $d$ is the grain size exponent, $n=1 / m$ is the true stress exponent. $k T$ has its usual meaning.

Elongation to failure and strain rate sensitivity

Table 1 values estimated at $420{ }^{\circ} \mathrm{C}$

\begin{tabular}{|c|c|c|c|c|}
\hline \multirow{2}{*}{$\dot{\varepsilon}\left(\mathrm{s}^{-1}\right)$} & \multicolumn{2}{|c|}{ QE22 } & \multicolumn{2}{c|}{ EZ33 } \\
\cline { 2 - 5 } & $\varepsilon_{f}(\%)$ & $\mathrm{m}$ & $\varepsilon_{f}(\%)$ & $\mathrm{m}$ \\
\hline $1 \times 10^{-4}$ & 720 & 0.62 & 700 & 0.65 \\
\hline $3 \times 10^{-4}$ & 780 & 0.75 & 710 & 0.73 \\
\hline $5 \times 10^{-4}$ & 450 & 0.50 & 420 & 0.50 \\
\hline $1 \times 10^{-3}$ & 360 & 0.42 & 340 & 0.48 \\
\hline $5 \times 10^{-3}$ & 300 & 0.38 & 280 & 0.35 \\
\hline 0.01 & 240 & 0.32 & 230 & 0.30 \\
\hline
\end{tabular}

$D$ is the appropriate diffusion coefficient $\left(=D_{0} \exp (-Q / R T)\right.$, where $D_{0}$ the frequency factor, $Q$ the activation energy for the diffusion process and $R$ the gas constant). The steady state plastic flow of coarse-grained metals at high temperatures, above $0.4 T_{M}$ ( $T_{M}$ being the melting temperature), is usually described by dislocation motion and storage on obstacles. These obstacles may be either of non-dislocation type or of dislocation type. Grain boundaries or incoherent precipitates are considered as the obstacles of the non-dislocation type. Dislocation type obstacles are formed by reactions between various types of dislocations. Steady state character of deformation is provided with the dislocation cross slip and also by climbing of dislocation edge segments. In the fine grained materials two other independent mechanisms - grain boundary sliding accommodated by slip and directional diffusional flow may be considered [25-27]. Each of the three deformation mechanisms has specific values of $n, p$ and $Q$ by which the mechanism can be uniquely defined. For the plastic flow by slip of dislocation the high values of the stress exponent ( $n=5$ or higher) are characteristic and the activation energy is close to values for the activation energy of the lattice diffusion or for the pipe diffusion. The grain size exponent $p$ is close to zero [28]. Grain boundary sliding accommodated by dislocation slip or diffusional flow is characterised by the low values of the stress exponent (lower than 3 , in the case of ideal superplasticity 1) and the activation energy is equal to the lattice or grain boundary diffusion or combination both. As no dislocations were observed by means of TEM and the estimated values of the stress sensitivity parameter are 1.33 (QE22) and 1.37 (EZ33) we may conclude that the main deformation mechanism during the superplastic flow is the grain boundary sliding accommodated by lattice and grain boundary diffusion.

\subsection{Plasticity of WE54/SiCp composite.}

The strain rate sensitivity parameter $m$ was measured in SRC tests. The values of $m$ estimated for different strain rates and tem- 


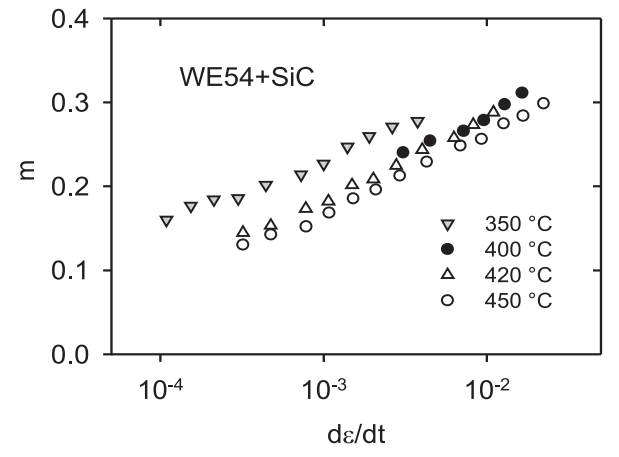

Fig. 7 Strain rate dependence of m-parameter

peratures are introduced in Fig. 7. The strong strain rate dependence of the m-parameter is obvious from the figure. With increasing temperature the dependence is shifted to the higher strain-rates. However, the $m$ parameter slightly increases with temperature; the maximum values are in the vicinity of 0.3 as it is obvious from Table 2. The maximum recorded elongation to failure was $99 \%$, which shows an evidence of the enhanced plasticity, nevertheless this value remains below the bottom limit for superplastic region. The SEM micrograph of the sample exhibiting the highest elongation is shown in Fig. 8 documenting the microstructure after deformation at $450{ }^{\circ} \mathrm{C}$. Numerous cavities formed during the high temperature deformation are visible in Fig. 8. The cavitation primarily occurred at the reinforcement/matrix interfaces which are

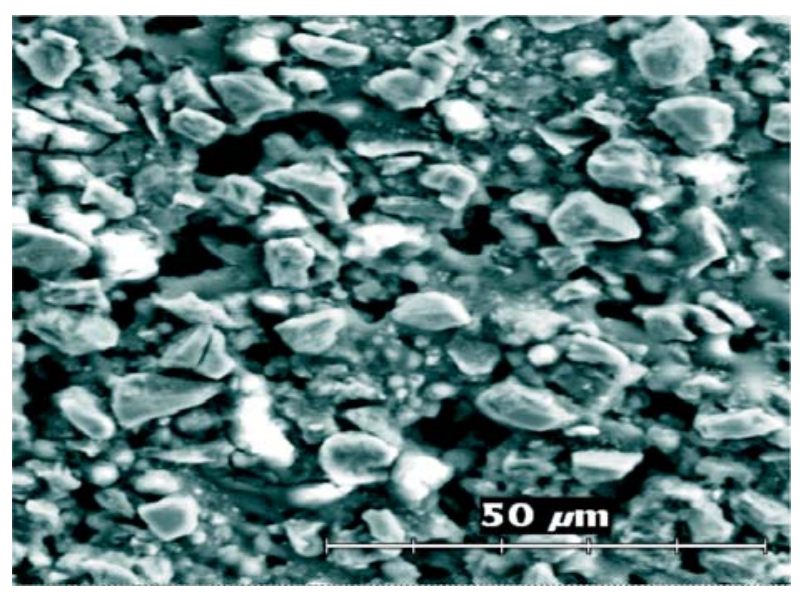

Fig. 8 Micrograph showing cavities formed during high temperature deformation

the preferential sites for the nucleation of cavities. The density of cavities was higher near the fracture surface where elongated cavities were found. Since many of these cavities were fairly large, it is reasonable to assume that the growth and subsequent coalescence and interlinkage of the cavities led to a premature failure.

As it is obvious from Fig. 8 the m-values decrease with decreasing strain rate at low strain rates down to $\sim 0.1$. Low $m$-values in
Maximum values of m-parameter and elongation to failure estimated for three temperatures and corresponding strain rates for $\mathrm{WE} 54 / \mathrm{SiC}$ composite

\begin{tabular}{|c|c|c|c|c|}
\hline Temperature & $m_{\max }$ & $\dot{\varepsilon}\left(\mathrm{s}^{-1}\right)$ & $\varepsilon_{f}(\%)$ & $\sigma_{\text {th }}(\mathrm{MPa})$ \\
\hline $350{ }^{\circ} \mathrm{C}$ & 0.28 & $4 \times 10-3$ & 66 & 11.2 \\
\hline $420{ }^{\circ} \mathrm{C}$ & 0.30 & $2 \times 10-2$ & 95 & 6.6 \\
\hline $450{ }^{\circ} \mathrm{C}$ & 0.29 & $5 \times 10-2$ & 99 & 4.7 \\
\hline
\end{tabular}

the low strain rate regime were generally reported for PM magnesium alloys and Mg based composites [29-32]; they are probably associated with the existence of the threshold stresses $\sigma_{t h}$ [33]. Considering the threshold stress, eq. (1) can be rewritten as

$$
\dot{\varepsilon}=A \frac{G b}{k T}\left(\frac{b}{d}\right)^{p}\left(\frac{\sigma-\sigma_{t h}}{G}\right)^{n} D
$$

The $\sigma_{t h}$ may be determined by adopting a plot of steady state stress $\sigma$ against $\dot{\varepsilon}^{1 / n}(n=1,2,3,5)$ in a double linear scale [34]. The best linear fit in the entire temperature range was found for $n=3$. By extrapolation to zero strain-rate (see Fig. 9) the threshold stress values were estimated for various temperatures and are introduced in Table 2.

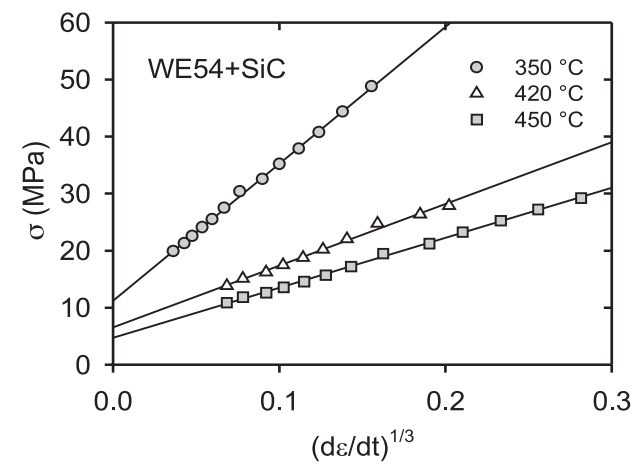

Fig. 9 Estimation of the threshold stress

From Table 2 it follows that the threshold stress decreases with increasing temperature. The temperature dependence of the normalised threshold stress may be expressed by an Arrhenius-type relationship in the form [35]

$$
\frac{\sigma_{t h}}{G}=B \exp \left(\frac{Q_{0}}{R T}\right) \text {. }
$$

Here $B$ is constant and $Q_{0}$ is an energy term which appears to be associated with the deformation process. The activation energy $Q_{0}$ was estimated from the plot $\ln \dot{\varepsilon} T / G$ vs $1 / T$ (Fig. 10), measured at a constant normalized flow stress $\left(\sigma-\sigma_{t h}\right) / G\left(\sigma-\sigma_{t h} / G=\right.$ $=1.7 \times 10^{-3}$ ). The activation energy was found to be $Q \approx 114$ $\mathrm{kJ} / \mathrm{mol}$. The activation energy estimated for volume diffusion is $135 \mathrm{~kJ} / \mathrm{mol}$ and for grain boundary diffusion $92 \mathrm{~kJ} / \mathrm{mol}$ [36]. Comparing with the experimental value of $114 \mathrm{~kJ} / \mathrm{mol}$ (using rule of mixture), we may conclude that the measured activation energy 


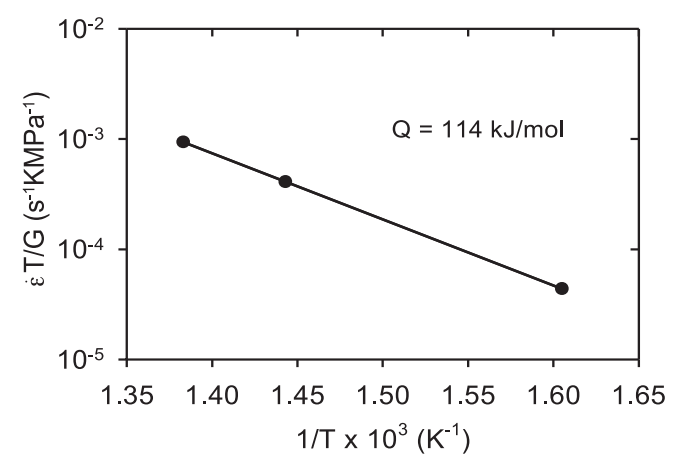

Fig. 10 Estimation of the activation energy

consists of approximately $50 \%$ volume and $50 \%$ grain boundary diffusion. The threshold stress is very probably necessary for the dislocation slip in the basal planes dependent on cross slip into non-basal slip planes (pseudo-Peierls mechanism), and/or grain boundary sliding.

Observed formation and growth of cavities relaxes the stress concentration caused at the particles on sliding grain boundaries. Cavities, created by vacancy clustering, may nucleate if the stress concentration is not relieved sufficiently rapidly. Local tensile stress caused by sliding at interfaces may be written in the form [4]

$$
\sigma_{\text {slid }}=\frac{0.92 k T d_{p} \dot{\varepsilon} d V_{f}}{\Omega D_{L}\left(1+5 \frac{\delta D_{G B}}{d_{p} D_{L}}\right)},
$$

where $d_{p}$ is the particle diameter, $\dot{\varepsilon}$ is the strain rate, $d$ is the grain size, $D_{L}$ is lattice diffusion and $D_{G B}$ the grain boundary diffusion coefficient, $\delta$ is grain boundary width, $\Omega$ is atomic volume and $V_{f}$ is the volume fraction of particles. The insufficiently accommodated grain boundary sliding process is the reason for cavitation and early failure of samples

\section{Conclusions}

1. Magnesium alloys QE22 and EZ33 exhibit superplastic behaviour at $420^{\circ} \mathrm{C}$ and the strain rates in the interval $1-3 \times 10^{-4}$ $\mathrm{s}^{-1}$.

2. The grain size refinement in alloys may be attributed to very stable $\mathrm{Mg}_{3}(\mathrm{Ag}, \mathrm{Nd})$ phase and $T$ phase in grain boundaries formed in both materials during the preparation process.

3. Small addition of $\mathrm{Zr}$ particles significantly influences the resulting grain size.

4. $\mathrm{SiC}$ particles very probably inhibit the grain boundary sliding and they are reason for the premature failure of the WE $54 / \mathrm{SiC}_{\mathrm{p}}$ composite.

5. The threshold stress values found at temperatures $350-450{ }^{\circ} \mathrm{C}$ may be interpret as the stresses necessary for the glide of dislocations in the compact and non-compact planes and grain boundary sliding.

\section{Acknowledgements.}

The work is a part of activities of the Charles University Research Center "Physics of Condensed Matter and Functional Materials". The authors are grateful also for the financial support of the Czech Grant Agency under the contract P108/12/J018.

\section{References}

[1] MOHRI, M., MABUCHI, T. M., SAITO, N., NAKAMURA. M.: Mater. Sci. Engn. A 257, 1998, 287.

[2] KAIBYSHEV, O. A. Superplasticity of Alloys, Intermetallics and Ceramics. Berlin Heidelberg: Springer Verlag; 1992.

[3] KIM, J. W., CHUNG, S. W., CHUNG, C. S., KUM, D.: Acta Mater. 49, 2001, 3337.

[4] MABUCHI, M., HIGASHI, K.: Acta Mater. 47, 1999, 1915.

[5] ROSOCHOWSKI, A.: Solid State Phenomena 101-102, 2005; 13.

[6] ZHU, Y. T., LANGDON, T. G.: JOM; 58-63, 2004, 58.

[7] ZEHETBAUER, M. J.: Adv. Eng. Mater. 5, 2003; 265.

[8] FIGUEIREDO, R. B., LANGDON, T. G.: Mater. Sci. Eng. A, 430, 2006, 151.

[9] MATSUBARA, K., MIYAHARA, Y., HORITA, Z., LANGDON, T. G.: Acta Mater., 51, 2003, 3073.

[10] LEE, S. W., CHEN, Y. L., WANG, H. Y., YANG, C. F., YEH, J. W.: Mater. Sci. Eng. A, 464, $2007,76$.

[11] TAN, J. C., TAN, M. J.: Mater. Sci. Eng. A 339, 2003, 81.

[12] WANG, Y. N., HUANG, J. C.: Mater. Trans. 44, 2003, 2276.

[13] WEI, Y. H., WANG, Q. D., ZHU, Y. P., ZHOU, H. T., DING, W. J., CHINO, Y., MABUCHI, M.: Mater. Sci. Eng. A 360, $2003,107$.

[14] KAWASAKI, M., KUBOTA, K., HIGASHI, K., LANGDON, T. G.: Mater. Sci. Eng. A 429, 2006, 334.

[15] SIVAKESAVAM, O., PRASAD, Y. V. R. K: Mater. Sci. Eng. A323, 2002, 270.

[16] YIN, D. L., ZHANG, K. F., WANG, G. F., HAN, W. B.: Mater. Letters 59, $2005,1714$.

[17] NAKASHIMA, K., IWASAKI, H., MORI, K. T., MABUCHI, M., NAKAMURA, M., ASAHINA, T.: Mater. Sci. Eng. A 293, 2000, 15.

[18] WESLING, V., RYSPAEV, T., SCHRAM, A.: Mater. Sci. Eng. A 462, 2007, 144.

[19] SZARAZ, Z., TROJANOVA, Z., RYSPAEV, T., WESLING, V.: Kovove Mater. 46, 2008, 285. 
[20] BOOESHAGHI, F., GARMESTANI, H.: Scripta Mater. 40, 1999; 509.

[21] SVOBODA, M., PAHUTOVA, M., MOLL, F., BREZINA, J., SKLENICKA, V.: In: Magnesium Alloys and their Applications. Weinheim; Wiley-VCH Verlag; 2000, p. 234.

[22] WIE, LIY., DUNLOP, G.L., WESTENGEN, H.: J. Mater. Sci. 32, 1995, 3335.

[23] EMLEY EF.: Principles of Magnesium Technology. Oxford: Pergamon Press; 1966, p. 127.

[24] DAS, A, LIU, G, FAN, Z.: Mater. Sci. Eng. A 419, 2006; 349.

[25] MUKHERJEE, A. K.: Mater. Sci. Eng., 8, 1971, 83.

[26] METENIER, P., GONZALEZ-DONCEL, G., RUANO, O.A., WOLFENSTINE, J., SHERBY, O.D.: Mater. Sci. Eng. A 12, $199,195$.

[27] BUSSIBA, A., BEN ARTZY, A., SHTECHMAN, A., IFERGAN, S., KUPIEC, M.: Mater. Scie. Eng. A302, 2001, 56.

[28] MUKHERJEE, A. K., BIRD, J. E., DORN, J. E.: Trans. Am. Soc. Met., 62, 1969, 155.

[29] MABUCHI, M., ASAHINA, T., IWASAKI, H., HIGASHI, K.: Mater. Sci. Technol. 13, 1997, 825.

[30] WATANABE, H., MUKAI, T., NIEH, T. G., HIGASHI, K.: Scripta Mater. 42, 2000, 249.

[31] WATANABE, H., MUKAI, T., MABUCHI, M., HIGASHI, K.: Acta Mater. 49, 2001, 2027.

[32] HIGASHI, K., MABUCHI, M., LANGDON, T. G.: ISIJ Int. 36, 1996, 1423.

[33] MOHAMED, F. A.: J. Mater. Sci. 18, 1983, 582.

[34] LI, Y., LANGDON, T. G.: Acta Mater. 47, 1999, 3395.

[35] MOHAMED F. A., PARK, K.-T., LAVERNIA, E. J.: Mater. Sci. Eng. A 150, 1992, 21.

[36] FROST, H.J., ASHBY, M. F., Deformation-mechanism Maps. Pergamon Press, Oxford, UK, 1982, 44. 